\title{
Potential therapeutic value of primary tumor resection in ampullary cancer patients with distant metastases at initial diagnosis: a population-based study
}

This article was published in the following Dove Press journal: Cancer Management and Research

Jie Wang',*
Xiaobo Bol,*
Pinxiang Lu',*
Tao Suo'
Xiaoling Ni'
Han Liu'
Hongtao Pan'
Sheng Shen'
Min Li'
Dexiang Zhang ${ }^{2}$
Yueqi Wang'
Houbao Liu'
'Department of General Surgery,
Zhongshan Hospital, Fudan University,
Shanghai, China; ${ }^{2}$ Department of
General Surgery, Xuhui Central
Hospital, Shanghai, China
*These authors contributed equally to
this work

*These authors contributed equally to

Correspondence: Yueqi Wang; Houbao Liu Department of General Surgery, Zhongshan Hospital, Fudan University, No. 180 Fenglin Road, Shanghai 200032, China

Email yueqiwang@fudan.edu.cn; houbaoliu@aliyun.com
Objective: To evaluate the therapeutic value of primary tumor resection (PTR) in metastatic ampullary cancer at the initial presentation.

Patients and methods: Patients with metastatic ampullary cancer were identified from Surveillance, Epidemiology and End Results database. Propensity score matching (PSM) was performed to balance the characteristics of our cohort. Kaplan-Meier analyses, log-rank tests and multivariate Cox regression models were employed to evaluate the therapeutic value of PTR. Results: A total of 346 patients with metastatic ampullary cancer were identified from 2004 to 2014 and 90 patients were screened by PSM. PTR was associated with favorable overall survival (OS) and cancer-specific survival (CSS) after PSM (PTR vs no-PTR: $16.0,95 \%$ CI: 9.0-22.0 vs 8.0, 95\% CI: 5.0-11.0 for median OS; 22.0 , 95\% CI: $13.0-33.0$ vs $9.0,95 \%$ CI: 5.0-11.0 for median CSS; both log-rank $P<0.001$ ). Patients receiving PTR plus chemotherapy showed better survival compared with those receiving only chemotherapy (median OS: 18, 95\% CI: $13-27$ vs 9.0, 95\% CI: 8.0-11.0; median CSS: 23.0 , 95\% CI: $14.0-36.0$ vs $9.0,95 \%$ CI: 8.0-13.0; both log-rank $P<0.001$ ).

Conclusion: PTR might bring a survival benefit to ampullary cancer patients with distant metastasis at the initial presentation and might provide a more favorable prognosis when combined with chemotherapy.

Keywords: ampullary cancer, PSM, primary tumor resection, chemotherapy

\section{Introduction}

Ampullary carcinomas are malignancies arising in the vicinity of the ampulla of Vater, a confluence of the distal common bile duct and the main pancreatic duct into the duodenum. Primary tumors of the ampulla of Vater are rather rare with an incidence of nearly five per million population and account for just $6 \%$ of periampullary cancer. ${ }^{1,2}$ Complete surgical resection is the only curative way of treating ampullary carcinomas. ${ }^{3,4}$ Due to the earlier presentation of biliary obstruction and other symptoms, there are higher resectability rates and higher 5-year survival rates in ampullary cancer than in other periampullary cancers, namely, pancreatic head cancer and distal cholangiocarcinoma. ${ }^{5,6}$

However, there are always a small minority of patients with metastasis at initial diagnosis who experience a poor prognosis with a 5 -year survival rate close to $0 \%{ }^{7}$ Because of the rarity of this disease, the optimal management for systemic therapy 
such as standard chemotherapy regimen has not been well established for these advanced cancer patients. ${ }^{8,9}$ In view of the disappointing efficacy of current approaches, other therapeutic methods need to be explored in the future.

A large body of researches have reported the favorable role of primary tumor resection (PTR) in some advanced cancers such as breast cancer, ${ }^{10}$ bladder cancer, ${ }^{11}$ head and neck squamous cell cancer and colorectal cancer. ${ }^{12-14}$ Palliative bypass surgery was carried out in some advanced periampullary cancer patients for the purpose of relieving symptoms and resulted in improved quality of life. ${ }^{15}$ However, there is still no population-based study to explore the survival prolongation after PTR, particularly in advanced ampullary cancer.

Hence, we used population-based data from Surveillance, Epidemiology and End Results (SEER) database to assess the therapeutic value of PTR in metastatic ampullary cancer at the initial presentation and explore the combined power of PTR plus chemotherapy.

\section{Patients and methods Study population}

Eligible patients were screened from the SEER database. The inclusion criteria are listed as follows: 1) ampullary cancer as the first primary cancer; 2) the cancer diagnosed between 2004 and 2014 because detailed information on tumor size was not available before 2004 and the cutoff follow-up date of the latest released SEER data was December 31, 2014; 3) ampullary cancer patients with distant metastasis at the initial presentation; 4) age at diagnosis older than 18 and younger than 80 (97 patients were excluded, including 3 patients receiving PTR); 5) definite information on whether patients received PTR (6 patients were excluded, as 5 of them did not record what surgery they did and 1 patient did not record whether the surgery was done); 6) survival time was at least 1 month to reduce selection bias (23 patients were excluded and none of them received PTR); 7) patients without death certificate were excluded ( 5 patients were excluded and none of them received PTR); these are presented in Figure 1. The data accessed from the SEER database are freely available. This study was approved by the Research Medical Ethics Committee Institutional Review Boards of Fudan University Zhongshan Hospital.

\section{Covariates and outcomes}

Baseline characteristics including age, sex and race, tumor grade, tumor size, $\mathrm{T}$ stage, $\mathrm{N}$ stage, PTR, radiotherapy and chemotherapy were collected. PTR referred to partial or total

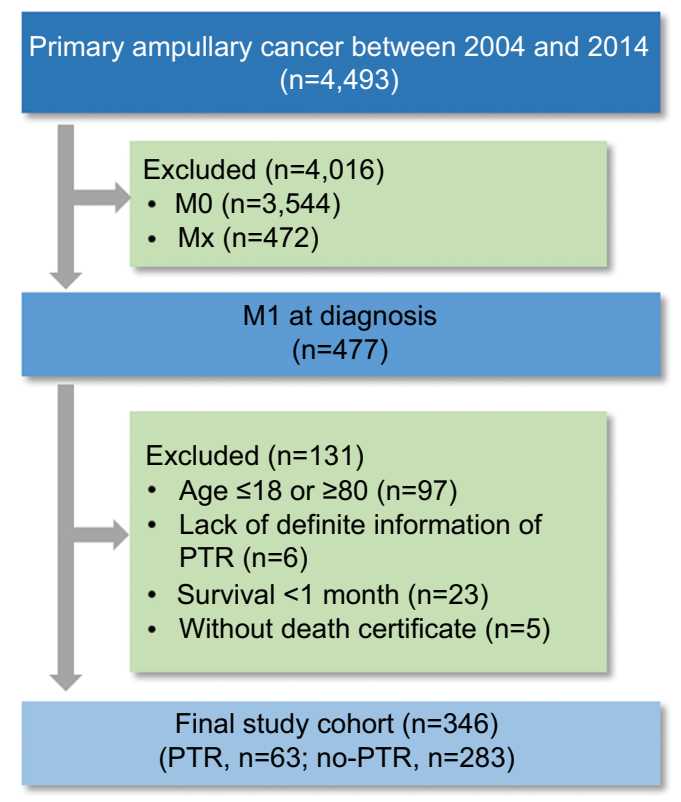

Figure I Flowchart of inclusion and exclusion in the study. Abbreviation: PTR, primary tumor resection.

surgical removal of the primary tumor with or without an en bloc resection of other organs, but not local tumor destructive methods such as laser excision and excisional biopsy. Radiotherapy referred to external beam radiation therapy, radioactive implants and radioisotopes. Histologic type was not incorporated in the analyses because $>90 \%$ of those patients represent adenocarcinoma. Histologic subtypes such as "pancreaticobiliary subtypes" and "intestinal subtypes" were also not incorporated in the analyses due to the lack of available data within the SEER database. Patients with unknown tumor size or grade were recorded as "Unspecified". The primary endpoints of the study were overall survival (OS) and cancerspecific survival (CSS). Survival time was calculated from the date of diagnosis to the date of death or the last follow-up.

\section{Statistical analysis}

Continuous variables were compared by Student's $t$-test and categorical variables by Pearson's chi-squared test or Fisher's exact test, as indicated. A one-to-one propensity score matching (PSM) with a caliper of 0.005 was performed to ensure that the characteristics of the PSM cohort were balanced. Kaplan-Meier methods and log-rank tests were used to assess the significant differences in OS and CSS. Multivariate Cox proportional hazards regression analysis was employed to evaluate the prognostic factors, and HRs along with 95\% CI were calculated. Student's $t$-test, Pearson's chi-squared test, Fisher's exact test, PSM and multivariate Cox regression analyses were performed by IBM SPSS version 22 (IBM 
Corporation, Armonk, NY, USA). Kaplan-Meier survival curves and log-rank tests were conducted by GraphPad Prism 7.0 (GraphPad Software, Inc., San Diego, CA, USA). Forest plots summarizing HRs for PTR vs no-PTR in the subgroup multivariate analyses were performed by $\mathrm{R}$ program version 3.4.0 (http://www.r-project.org). A two-sided $P$-value $<0.05$ indicated statistical significance.

\section{Results}

\section{Study cohort selection and baseline characteristics}

In total, 346 patients with metastatic ampullary cancer at the initial presentation were enrolled in our study. Among the 346 patients, PTR was carried out in less than one-fifth of the overall patients $(n=63,18.2 \%)$. The mean age at diagnosis was
63.4 years. Almost two-thirds $(n=231,66.8 \%)$ of the patients received chemotherapy, while only one-ninth $(n=38,11.0 \%)$ of the patients received radiotherapy. Baseline characteristics across PTR and no-PTR groups are shown in Table 1. Significant differences $(P<0.05)$ were observed in the race, tumor size, grade, $\mathrm{T}$ stage and $\mathrm{N}$ stage. To balance the characteristics of the two cohorts and reduce the selection bias as much as possible, PSM was performed on the basis of the above factors (race, tumor size, grade, $\mathrm{T}$ stage and $\mathrm{N}$ stage). As shown in Table 2, a total of 90 patients were included finally, and all the characteristics of the PSM cohort were balanced.

\section{Therapeutic value of PTR in the overall cohort}

The effect of PTR on OS and CSS was evaluated in the overall cohort and the PSM cohort. As shown in Figure 2, the survival

Table I Baseline characteristics of metastatic ampullary cancer patients before PSM

\begin{tabular}{|c|c|c|c|c|}
\hline \multirow[t]{2}{*}{ Characteristics } & \multirow{2}{*}{$\begin{array}{l}\text { Total } \\
(n=346)\end{array}$} & \multirow{2}{*}{$\begin{array}{l}\text { PTR } \\
(n=63)\end{array}$} & \multirow{2}{*}{$\begin{array}{l}\text { No-PTR } \\
(n=283)\end{array}$} & \multirow[t]{2}{*}{$P$-value } \\
\hline & & & & \\
\hline Age at diagnosis & & & & 0.179 \\
\hline Mean \pm SD & $63.4 \pm 10.7$ & $61.8 \pm 10.8$ & $63.8 \pm 10.6$ & \\
\hline Sex & & & & 0.442 \\
\hline Female & | 44 (4I.6\%) & $23(36.5 \%)$ & I2I (42.8\%) & \\
\hline Male & 202 (58.4\%) & 40 (63.5\%) & $162(57.2 \%)$ & \\
\hline Race & & & & 0.009 \\
\hline White & $26 I(75.4 \%)$ & $38(60.3 \%)$ & $223(78.8 \%)$ & \\
\hline Black & 47 (I3.6\%) & 14 (22.2\%) & 33 (11.7\%) & \\
\hline Other & 38 (I I.0\%) & I I (I7.5\%) & $27(9.5 \%)$ & \\
\hline Tumor size, cm & & & & $<0.001$ \\
\hline$<3$ & $89(25.7 \%)$ & $28(44.4 \%)$ & 61 (2I.6\%) & \\
\hline$\geq 3$ & $102(29.5 \%)$ & 27 (42.9\%) & $75(26.5 \%)$ & \\
\hline Unspecified & $155(44.8 \%)$ & $8(12.7 \%)$ & |47 (5I.9\%) & \\
\hline Grade & & & & $<0.001$ \\
\hline High & $27(7.8 \%)$ & $6(9.5 \%)$ & $21(7.4 \%)$ & \\
\hline Moderate & 102 (29.5\%) & $24(38.1 \%)$ & 78 (27.6\%) & \\
\hline Low & 96 (27.7\%) & $30(47.6 \%)$ & $66(23.3 \%)$ & \\
\hline Unspecified & $121(35.0 \%)$ & $3(4.8 \%)$ & I I 8 (4I.7\%) & \\
\hline T stage & & & & $<0.001$ \\
\hline TI-2 & $120(34.7 \%)$ & 16 (25.4\%) & $104(36.7 \%)$ & \\
\hline T3 & $56(16.2 \%)$ & $20(31.7 \%)$ & 36 (12.7\%) & \\
\hline T4 & $96(27.7 \%)$ & $25(39.7 \%)$ & $71(25.1 \%)$ & \\
\hline Tx & $74(21.4 \%)$ & $2(3.2 \%)$ & $72(25.4 \%)$ & \\
\hline N stage & & & & $<0.001$ \\
\hline No & 152 (43.9\%) & 12 (19.0\%) & I 38 (47.8\%) & \\
\hline $\mathrm{N}+$ & $136(39.3 \%)$ & 49 (77.8\%) & 87 (30.7\%) & \\
\hline $\mathrm{Nx}$ & $58(16.8 \%)$ & $2(3.2 \%)$ & $56(19.8 \%)$ & \\
\hline Radiotherapy & & & & 0.250 \\
\hline No evidence & $308(89.0 \%)$ & $53(84.1 \%)$ & $255(90.1 \%)$ & \\
\hline Yes & 38 (1 I.0\%) & 10 (15.9\%) & $28(9.9 \%)$ & \\
\hline Chemotherapy & & & & 0.897 \\
\hline No evidence & 115 (33.2\%) & $21(33.3 \%)$ & 94 (33.2\%) & \\
\hline Yes & $231(66.8 \%)$ & 42 (66.7\%) & $189(66.8 \%)$ & \\
\hline
\end{tabular}

Notes: $P<0.05$ is considered statistically significant. Statistically significant values are shown in bold.

Abbreviations: PSM, propensity score matching; PTR, primary tumor resection. 
Table 2 Baseline characteristics of metastatic ampullary cancer patients after PSM

\begin{tabular}{|c|c|c|c|c|}
\hline \multirow[t]{2}{*}{ Characteristics } & \multirow{2}{*}{$\begin{array}{l}\text { Total } \\
(n=90)\end{array}$} & \multirow{2}{*}{$\begin{array}{l}\text { PTR } \\
(n=45)\end{array}$} & \multirow{2}{*}{$\begin{array}{l}\text { No-PTR } \\
(n=45)\end{array}$} & \multirow[t]{2}{*}{$P$-value } \\
\hline & & & & \\
\hline Age at diagnosis & & & & 0.457 \\
\hline Mean \pm SD & $62.3 \pm 11.3$ & $61.4 \pm 11.7$ & $63.2 \pm 10.9$ & \\
\hline Sex & & & & 0.519 \\
\hline Female & $36(40.0 \%)$ & 20 (44.4\%) & $16(35.6 \%)$ & \\
\hline Male & $54(60.0 \%)$ & 25 (55.6\%) & 29 (64.4\%) & \\
\hline Race & & & & 0.524 \\
\hline White & $60(66.7 \%)$ & $30(66.6 \%)$ & $30(66.7 \%)$ & \\
\hline Black & 19 (21.1\%) & $8(17.8 \%)$ & II (24.4\%) & \\
\hline Other & $\mathrm{II}(\mathrm{I} 2.2 \%)$ & 7 (15.6\%) & $4(8.9 \%)$ & \\
\hline Tumor size, cm & & & & 0.218 \\
\hline$<3$ & 34 (37.8\%) & 15 (33.3\%) & 19 (42.2\%) & \\
\hline$\geq 3$ & $36(40.0 \%)$ & $22(48.9 \%)$ & 14 (3I.I\%) & \\
\hline Unspecified & $20(22.2 \%)$ & $8(17.8 \%)$ & $12(26.7 \%)$ & \\
\hline Grade & & & & 0.119 \\
\hline High & $12(13.3 \%)$ & $4(8.9 \%)$ & $8(17.8 \%)$ & \\
\hline Moderate & $26(28.9 \%)$ & 15 (33.3\%) & II (24.4\%) & \\
\hline Low & 40 (44.4\%) & $23(51.1 \%)$ & 17 (37.8\%) & \\
\hline Unspecified & $12(13.4 \%)$ & $3(6.7 \%)$ & $9(20.0 \%)$ & \\
\hline T stage & & & & 0.339 \\
\hline TI-2 & $23(25.5 \%)$ & 10 (22.2\%) & 13 (28.9\%) & \\
\hline T3 & 25 (27.8\%) & $16(35.6 \%)$ & $9(20.0 \%)$ & \\
\hline $\mathrm{T} 4$ & 34 (37.8\%) & 17 (37.8\%) & $17(37.8 \%)$ & \\
\hline Tx & $8(8.9 \%)$ & $2(4.4 \%)$ & $6(13.3 \%)$ & \\
\hline N stage & & & & 0.180 \\
\hline No & 21 (23.3\%) & $10(22.2 \%)$ & II (24.4\%) & \\
\hline $\mathrm{N}+$ & $60(66.7 \%)$ & $33(73.3 \%)$ & 27 (60.0\%) & \\
\hline $\mathrm{Nx}$ & $9(10.0 \%)$ & $2(4.5 \%)$ & $7(15.6 \%)$ & \\
\hline Radiotherapy & & & & 0.771 \\
\hline No evidence & 76 (84.4\%) & 39 (86.7\%) & 37 (82.2\%) & \\
\hline Yes & 14 (I5.6\%) & $6(13.3 \%)$ & $8(17.8 \%)$ & \\
\hline Chemotherapy & & & & 0.060 \\
\hline No evidence & 25 (27.8\%) & 17 (37.8\%) & 8 (17.8\%) & \\
\hline Yes & 65 (72.2\%) & 28 (62.2\%) & 37 (82.2\%) & \\
\hline
\end{tabular}

Notes: PSM was performed according to race, tumor size, grade, $T$ stage and $\mathrm{N}$ stage with a caliper of 0.005 . $P<0.05$ is considered statistically significant. Abbreviations: PSM, propensity score matching; PTR, primary tumor resection.

analysis by log-rank test showed PTR was significantly associated with improved survival for the overall cohort (PTR vs no-PTR: $18.0,95 \% \mathrm{CI}: 13.0-23.0$ vs $7.0,95 \% \mathrm{CI}: 6.0-8.0$ for median OS; 21.0 , 95\% CI: $14.0-27.0$ vs $7.0,95 \% \mathrm{CI}$ : 6.0-8.0 for median CSS; both log-rank $P<0.001)$ and the PSM cohort (PTR vs no-PTR: 16.0, 95\% CI: 9.0-22.0 vs 8.0, 95\% CI: 5.0-11.0 for median OS; 22.0, 95\% CI: 13.0-33.0 vs 9.0, 95\% CI: 5.0-11.0 for median CSS; both log-rank $P<0.001)$. Baseline characteristics of the overall cohort and the PSM cohort are presented in Tables S1 and S2. After adjusting for other covariates, PTR still acted as a favorable predictor for both OS and CSS (PTR vs no-PTR, HR: 0.365, 95\% CI: $0.251-0.531, P<0.001$ for OS; HR: $0.331,95 \% \mathrm{CI}$ : $0.223-0.492, P<0.001$ for CSS), as shown in Table 3.
Therapeutic value of combination of PTR and chemotherapy

As chemotherapy is the most commonly used method for advanced ampullary cancer patients for the time being, we evaluated its therapeutic effect in the meantime. As shown in Figure S1 and Figure 3A, patients receiving chemotherapy showed a survival benefit compared with patients not receiving chemotherapy, no matter before PSM (chemotherapy vs no chemotherapy: $10.0,95 \%$ CI: $8.0-13.0$ vs $4.0,95 \%$ CI: 3.0-5.0 for median OS; 10.0, 95\% CI: 8.0-14.0 vs 4.0, 95\% CI: 3.0-5.0 for median CSS; both log-rank $P<0.001$ ) or after PSM (chemotherapy vs no chemotherapy: 10.0, 95\% CI: $8.0-13.0$ vs 4.0 , 95\% CI: 3.0-5.0 for median OS; 10.0 , 95\% CI: $8.0-14.0$ vs 4.0, 95\% CI: $3.0-5.0$ for median CSS; 
A

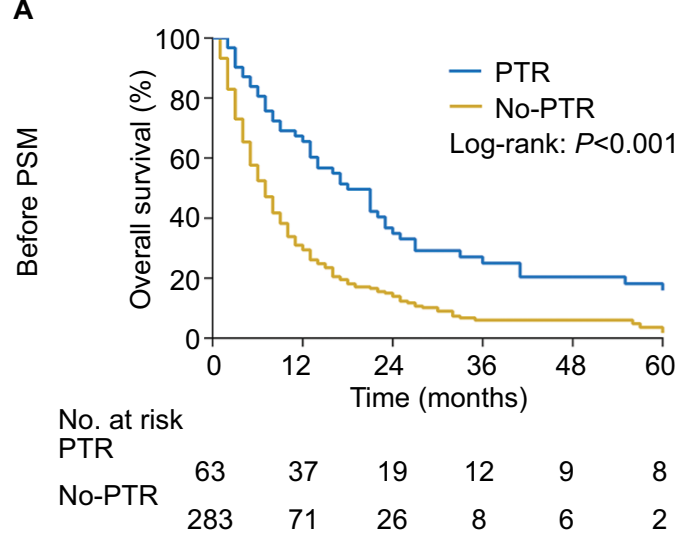

B

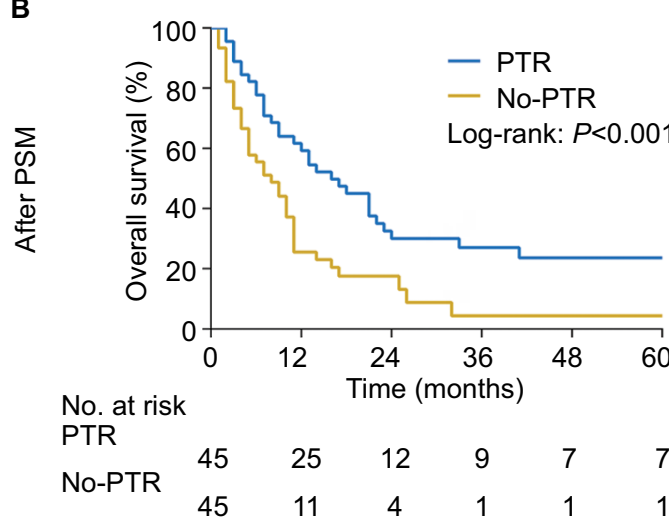

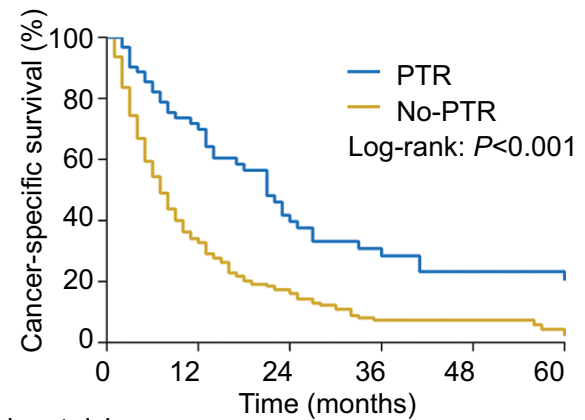

No. at risk

$\begin{array}{llllll}\text { PTR } & \text { No-PTR } \\ 283 & 37 & 19 & 12 & 9 & 8 \\ 283 & 71 & 26 & 8 & 6 & 2\end{array}$

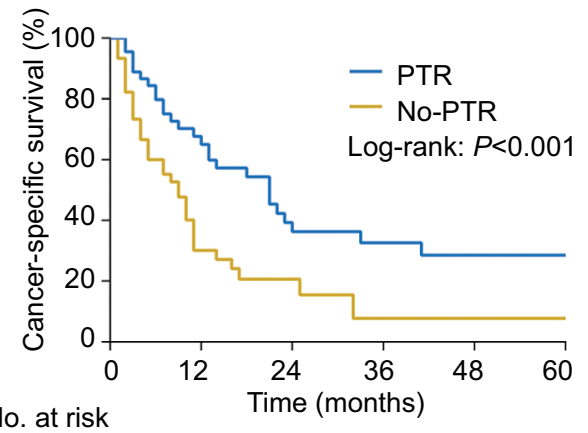

PTR

$\begin{array}{ccccccc}\text { No-PTR } & 45 & 25 & 12 & 9 & 7 & 7 \\ & 45 & 11 & 4 & 1 & 1 & 1\end{array}$

Figure 2 Kaplan-Meier curves of overall and cancer-specific survival according to whether PTR was performed or not in the overall cohort before PSM ( $\mathrm{n}=346$ ) (A) and the PSM cohort after PSM ( $n=90)(B)$.

Abbreviations: PSM, propensity score matching; PTR, primary tumor resection.

both log-rank $P<0.001)$. The baseline characteristics of the whole cohort and the PSM cohort are shown in Tables S1 and S2. Simultaneously, chemotherapy is still an independent favorable prognostic factor after the multivariate analysis, in accordance with previous clinical trials (Table 3$){ }^{9}$

Furthermore, it was found that the therapeutic effect of PTR still existed regardless of receiving chemotherapy or not on multivariate analyses within chemotherapy subgroups (PTR vs no-PTR in "chemotherapy” group, HR: 0.447, 95\% CI: 0.282-0.709 for OS; HR: 0.397, 95\% CI: 0.243-0.649 for CSS; PTR vs no-PTR in "no chemotherapy" group, HR: 0.259 , 95\% CI: $0.129-0.521$ for OS; HR: 0.233 , 95\% CI: 0.113-0.481 for CSS), as shown in Figure S2. In order to achieve the best therapeutic effect, we then considered whether patients could benefit more from the combination of PTR and chemotherapy or not. In the Kaplan-Meier curves, patients who received both PTR and chemotherapy showed a better survival advantage compared to patients only receiving chemotherapy (median OS: $18,95 \% \mathrm{CI}: 13-27$ vs 9.0 , 95\% CI: 8.0-11.0; median CSS: 23.0, 95\% CI: 14.0-36.0 vs $9.0,95 \% \mathrm{CI}$ : $8.0-13.0$; log-rank $P<0.001)$, as shown in
Figure 3B. Furthermore, we also noticed the high percentage of patients alive at 5 years in the group treated by surgery and chemotherapy compared with patients only receiving chemotherapy $(11.9 \%$ vs $1.1 \%, P<0.001)$.

\section{Therapeutic value of PTR in other subgroups}

Subsequently, subgroup analyses were separately performed according to $T$ stage and age at diagnosis, as they are the most easily available clinical information for advanced ampullary cancer patients. As shown in Figures S2 and S3, PTR still independently predicted favorable OS and CSS in all the T stage subgroups and age subgroups.

\section{Discussion}

In this study, we explored the therapeutic roles of PTR for metastatic ampullary cancer patients at the initial presentation using a large cohort of metastatic ampullary cancer patients. Most importantly, our study evaluated the prognostic efficacy of combination of PTR plus chemotherapy, which proved to be a more efficient strategy. The above findings differed from 
A

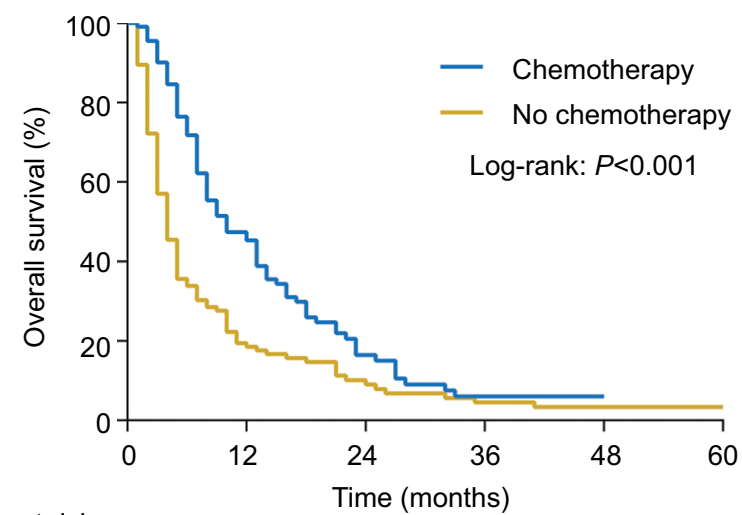

No. at risk

Chemotherapy

$\begin{array}{cccccc}115 & 42 & 12 & 3 & 0 & 0 \\ \begin{array}{c}\text { No chemotherapy } \\ 115\end{array} & 20 & 8 & 4 & 3 & 3\end{array}$

B

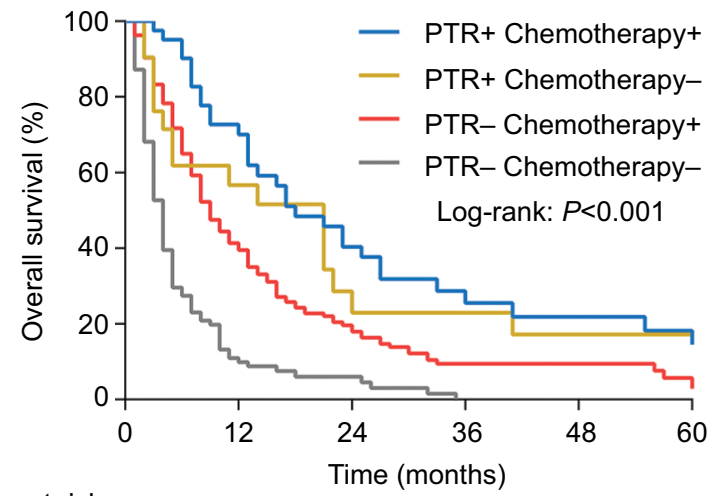

No. at risk

PTR+ Chemotherapy+

\begin{tabular}{|c|c|c|c|}
\hline 26 & 15 & 8 & 6 \\
\hline PTR+ Chemotherapy- & & & \\
\hline 11 & 4 & 4 & 3 \\
\hline PTR- Chemotherapy+ & & & \\
\hline 189 & 22 & 8 & 6 \\
\hline R- Chemotherapy- & & & \\
\hline 94 & 4 & 0 & 0 \\
\hline
\end{tabular}

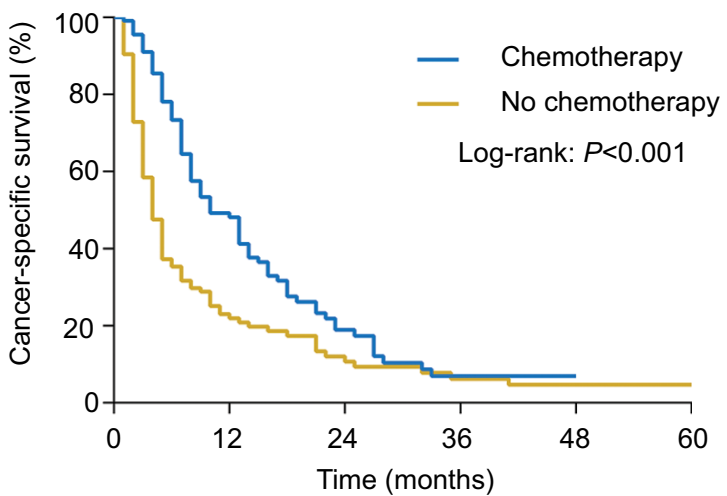

No. at risk

Chemotherapy

$\begin{array}{cccccc}115 & 42 & 12 & 3 & 0 & 0 \\ \text { No chemotherapy } & & & & 3 & 3\end{array}$

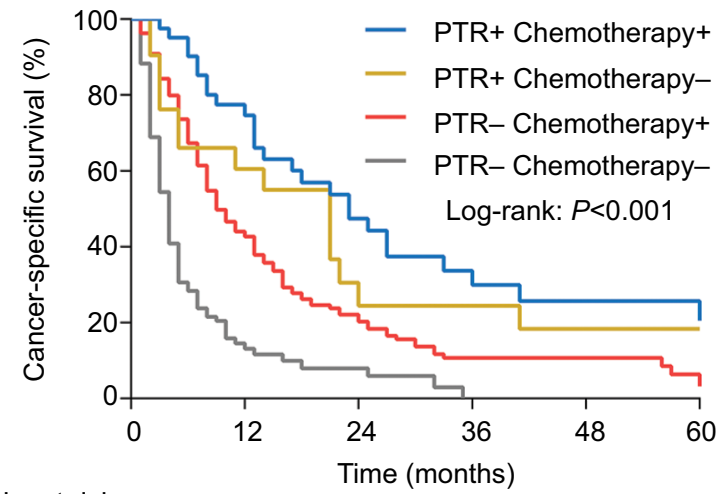

No. at risk

PTR+ Chemotherapy+

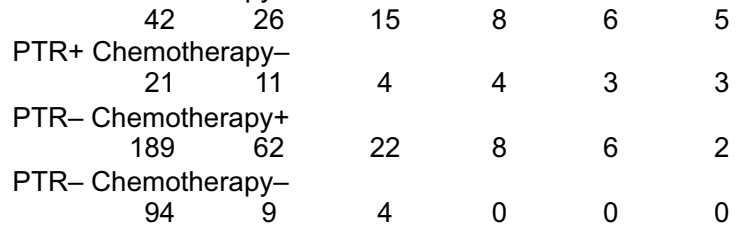

Figure 3 Kaplan-Meier curves of overall and cancer-specific survival according to whether chemotherapy was received or not in the PSM cohort ( $\mathrm{n}=230$ ) (A) and the status of combination of PTR and chemotherapy in the overall cohort $(n=346)(B)$.

Abbreviations: PSM, propensity score matching; PTR, primary tumor resection.

our original concept of management for metastatic ampullary cancer patients, but they might indeed provide us a new treatment option and could serve as the theoretical basis of further prospective studies.

Obstructive jaundice (80\%) caused by the compression of distal bile duct by the tumor is the most common presenting symptom of ampullary cancer. ${ }^{16,17}$ PTR could alleviate pruritus, anorexia, fat malabsorption, vitamin $\mathrm{K}$ deficiency and diarrhea through relieving obstructive jaundice to avoid coagulopathy, cholangitis, liver failure and cachexia. ${ }^{18} \mathrm{Up}$ to
$38 \%$ of patients die from biliary obstruction if no prophylactic treatment is administered. ${ }^{19}$ At the same time, alleviation of tumor load could reduce the risk of anemia, hypoproteinemia and cachexia too. ${ }^{20}$ On the other hand, primary tumor might be the source of seed and promote the development of new and existing metastases, whereby its removal might theoretically delay the tumor progression. ${ }^{21,22}$ However, there is not any consensus on the mechanism underlying the surgery-derived benefits, and the hypothesis given above needs to be validated in ampullary cancer. 
Table 3 Multivariate Cox regression models of prognostic factors for overall and cancer-specific survival

\begin{tabular}{|c|c|c|c|c|}
\hline \multirow[t]{2}{*}{ Characteristics } & \multicolumn{2}{|l|}{ Overall survival } & \multicolumn{2}{|c|}{ Cancer-specific survival } \\
\hline & HR (95\% Cl) & $P$-value & HR (95\% Cl) & $P$-value \\
\hline \multicolumn{5}{|l|}{ Age at diagnosis } \\
\hline For every I-year increase & $1.012(1.000-1.024)$ & 0.051 & $1.010(0.998-1.022)$ & 0.114 \\
\hline Sex & & & & \\
\hline Male vs female & $0.902(0.704-1.156)$ & 0.415 & $0.952(0.737-1.229)$ & 0.706 \\
\hline \multicolumn{5}{|l|}{ Race } \\
\hline Black vs white & $1.126(0.795-1.595)$ & 0.505 & $1.129(0.785-1.624)$ & 0.513 \\
\hline Other vs white & $0.980(0.670-1.434)$ & 0.917 & 0.991 (0.669-1.469) & 0.966 \\
\hline \multicolumn{5}{|l|}{ Tumor size, cm } \\
\hline$\geq 3$ vs $<3$ & $0.884(0.635-1.232)$ & 0.468 & $0.854(0.607-1.20 I)$ & 0.364 \\
\hline Unspecified vs $<3$ & $1.076(0.787-1.469)$ & 0.647 & $1.009(0.732-1.39 \mid)$ & 0.956 \\
\hline \multicolumn{5}{|l|}{ Grade } \\
\hline Moderate vs high & $1.559(0.972-2.50 \mathrm{I})$ & 0.053 & $1.555(0.950-2.543)$ & 0.079 \\
\hline Low vs high & 1.836 (1.128-2.987) & 0.014 & $1.829(1.101-3.039)$ & 0.020 \\
\hline Unspecified vs high & I.I82 (0.746-1.875) & 0.476 & $1.183(0.732-1.913)$ & 0.492 \\
\hline \multicolumn{5}{|l|}{ T stage } \\
\hline T3-4 vs TI-2 & $0.960(0.724-1.272)$ & 0.775 & $1.011(0.755-1.353)$ & 0.944 \\
\hline Tx vs TI-2 & $0.921(0.644-1.318)$ & 0.654 & $0.934(0.642-1.357)$ & 0.719 \\
\hline \multicolumn{5}{|l|}{ N stage } \\
\hline $\mathrm{N}+$ vs $\mathrm{N} 0$ & $1.205(0.902-1.609)$ & 0.264 & $1.213(0.898-1.638)$ & 0.208 \\
\hline Nx vs No & $1.429(1.004-2.034)$ & 0.048 & 1.438 (0.999-2.070) & 0.051 \\
\hline \multicolumn{5}{|l|}{ Radiation } \\
\hline Yes vs no evidence & $1.442(0.984-2.115)$ & 0.061 & $1.304(0.866-1.964)$ & 0.204 \\
\hline \multicolumn{5}{|l|}{ Chemotherapy } \\
\hline Yes vs no evidence & $0.472(0.365-0.609)$ & $<0.001$ & $0.465(0.357-0.606)$ & $<0.001$ \\
\hline \multicolumn{5}{|l|}{ Primary tumor resection } \\
\hline Yes vs no evidence & $0.365(0.25 \mathrm{I}-0.53 \mathrm{I})$ & $<0.001$ & $0.331(0.223-0.492)$ & $<0.001$ \\
\hline
\end{tabular}

Notes: $P<0.05$ is considered statistically significant. Statistically significant values are shown in bold.

As the dominant treatment for patients with metastasis, chemotherapy strategies such as the combination of gemcitabine and cisplatin represent significant survival benefits in some clinical trials, but a consensus about the therapeutic efficacy of these regimens has not been reached yet. ${ }^{9}$ Moreover, many of these clinical trials are combined series that include patients with pancreatic, biliary tract and ampullary cancer. ${ }^{8}$ In our study, we indeed noticed that patients receiving chemotherapy could experience a significant but modest survival advantage compared to others not receiving chemotherapy, although we could not further analyze the impact of chemotherapy as the details about chemotherapy regimens are not available. More interestingly, its conjunction with PTR could greatly improve the prognosis of patients. That is, the conjunction might provide both short- and long-term survival benefits. Hence, the more aggressive strategy of PTR plus chemotherapy might be taken into consideration for patients who could tolerate it. As we know, optimal management for systemic therapy has not well been established for these advanced cancer patients. Our finding might add a reasonable method and extend the treatment spectrum for them.

In spite of the intriguing results, some inevitable limitations must be shown clearly. The major limitation came from the SEER dataset itself. For instance, there was a lack of details concerning the surgical procedure, location and size of metastases, chemotherapy regimen and the clinical status of patients at initial diagnosis. Histologic subtype is an important prognostic factor in ampullary cancer, but there is still no detailed record in the SEER database. So, even though PSM was used, some bias might still exist. Finally, due to the retrospective nature of our study, prospective research needs to be conducted in the future.

In conclusion, this population-based study proved the potentially favorable influence of PTR on survival in advanced ampullary cancer patients at the initial presentation, and combined utilization of PTR plus chemotherapy might provide more favorable survival. 


\section{Acknowledgments}

This study was supported by grants from the National Natural Science Foundation of China (no. 81502004 and no. 81600630), the Foundation of Shanghai Science and Technology Committee (16411952000), JianFeng project of XuHui Provincial Commission of Health and Family Planning (SHXH201703 and SHXH201701) and the Shanghai Medical Discipline of Key Programs for General Surgery. All these study sponsors have no roles in the study design and in the collection, analysis and interpretation of data.

\section{Author contributions}

All authors contributed toward data analysis, drafting and critically revising the paper, gave final approval of the version to be published, and agreed to be accountable for all aspects of the work.

\section{Disclosure}

The authors report no conflicts of interest in this work.

\section{References}

1. Albores-Saavedra J, Schwartz AM, Batich K, Henson DE. Cancers of the ampulla of Vater: demographics, morphology, and survival based on 5,625 cases from the SEER program. J Surg Oncol. 2009;100(7): 598-605.

2. Goodman MT, Yamamoto J. Descriptive study of gallbladder, extrahepatic bile duct, and ampullary cancers in the United States, 1997-2002. Cancer Causes Control. 2007;18(4):415-422.

3. Hornick JR, Johnston FM, Simon PO, et al. A single-institution review of 157 patients presenting with benign and malignant tumors of the ampulla of Vater: management and outcomes. Surgery. 2011;150(2):169-176.

4. Bettschart V, Rahman MQ, Engelken FJ, Madhavan KK, Parks RW, Garden OJ. Presentation, treatment and outcome in patients with ampullary tumours. Br J Surg. 2004;91(12):1600-1607.

5. Roberts RH, Krige JE, Bornman PC, Terblanche J. Pancreaticoduodenectomy of ampullary carcinoma. Am Surg. 1999;65(11):1043-1048.

6. Sommerville CA, Limongelli P, Pai M, et al. Survival analysis after pancreatic resection for ampullary and pancreatic head carcinoma: an analysis of clinicopathological factors. J Surg Oncol. 2009;100(8): 651-656.
7. Beger HG, Treitschke F, Gansauge F, Harada N, Hiki N, Mattfeldt T. Tumor of the ampulla of Vater: experience with local or radical resection in 171 consecutively treated patients. Arch Surg. 1999;134(5):526-532.

8. Jiang ZQ, Varadhachary G, Wang X, et al. A retrospective study of ampullary adenocarcinomas: overall survival and responsiveness to fluoropyrimidine-based chemotherapy. Ann Oncol. 2013;24(9):2349-2353.

9. Valle J, Wasan H, Palmer DH, et al. Cisplatin plus gemcitabine versus gemcitabine for biliary tract cancer. $N$ Engl J Med. 2010;362(14): $1273-1281$.

10. Warschkow R, Güller U, Tarantino I, et al. Improved survival after primary tumor surgery in metastatic breast cancer: a propensity-adjusted, population-based SEER trend analysis. Ann Surg. 2016;263(6): $1188-1198$.

11. Dong F, Shen Y, Gao F, et al. Prognostic value of site-specific metastases and therapeutic roles of surgery for patients with metastatic bladder cancer: a population-based study. Cancer Manag Res. 2017;9: 611-626.

12. Shi X, Dong F, Wei W, et al. Prognostic significance and optimal candidates of primary tumor resection in major salivary gland carcinoma patients with distant metastases at initial presentation: A populationbased study. Oral Oncol. 2018;78:87-93.

13. Patel TD, Marchiano E, Chin OY, et al. Utility of surgery/radiotherapy in distant metastatic head and neck squamous cell carcinoma: a populationbased approach. Otolaryngol Head Neck Surg. 2016;154(5):868-874.

14. Tarantino I, Warschkow R, Worni M, et al. Prognostic relevance of palliative primary tumor removal in 37,793 metastatic colorectal cancer patients: a population-based, propensity score-adjusted trend analysis. Ann Surg. 2015;262(1):112-120.

15. Gurusamy KS, Kumar S, Davidson BR. Prophylactic gastrojejunostomy for unresectable periampullary carcinoma. Cochrane Database Syst Rev. 2013;2:CD008533.

16. Monson JR, Donohue JH, McEntee GP, et al. Radical resection for carcinoma of the ampulla of Vater. Arch Surg. 1991;126(3):353-357.

17. Smith RC. Surgical treatment for ampullary carcinoma. Aust $N Z J$ Surg. 1999;69(3):170-171.

18. Nakakura EK, Warren RS. Palliative care for patients with advanced pancreatic and biliary cancers. Surg Oncol. 2007;16(4):293-297.

19. Stark A, Hines OJ. Endoscopic and operative palliation strategies for pancreatic ductal adenocarcinoma. Semin Oncol. 2015;42(1):163-176.

20. Cook AD, Single R, McCahill LE. Surgical resection of primary tumors in patients who present with stage IV colorectal cancer: an analysis of surveillance, epidemiology, and end results data, 1988 to 2000. Ann Surg Oncol. 2005;12(8):637-645.

21. Khan SA, Stewart AK, Morrow M. Does aggressive local therapy improve survival in metastatic breast cancer? Surgery. 2002;132(4):620-627.

22. Pockaj BA, Wasif N, Dueck AC, et al. Metastasectomy and surgical resection of the primary tumor in patients with stage IV breast cancer: time for a second look? Ann Surg Oncol. 2010;17(9):2419-2426. 


\section{Supplementary materials}

Table SI Baseline characteristics of metastatic ampullary cancer patients before PSM

\begin{tabular}{|c|c|c|c|c|}
\hline \multirow[t]{2}{*}{ Characteristics } & Total & Chemotherapy & No chemotherapy & \multirow[t]{2}{*}{$P$-value } \\
\hline & $(n=346)$ & $(n=231)$ & $(n=115)$ & \\
\hline Age at diagnosis & & & & $<0.001$ \\
\hline Mean \pm SD & $63.4 \pm 10.7$ & $61.8 \pm 10.9$ & $66.7 \pm 9.4$ & \\
\hline Sex & & & & 0.667 \\
\hline Female & 144 (4I.6\%) & 98 (42.4\%) & $46(40.0 \%)$ & \\
\hline Male & $202(58.4 \%)$ & $133(57.6 \%)$ & $69(60.0 \%)$ & \\
\hline Race & & & & 0.604 \\
\hline White & $26 \mid(75.4 \%)$ & 178 (77.1\%) & $83(72.2 \%)$ & \\
\hline Black & $47(13.6 \%)$ & 29 (12.6\%) & $18(15.6 \%)$ & \\
\hline Other & 38 (1 I.0\%) & $24(10.3 \%)$ & 14 (I2.2\%) & \\
\hline Tumor size, cm & & & & 0.149 \\
\hline$<3$ & 89 (25.7\%) & $63(27.3 \%)$ & $26(22.6 \%)$ & \\
\hline$\geq 3$ & $102(29.5 \%)$ & 73 (3I.6\%) & 29 (25.2\%) & \\
\hline Unspecified & $155(44.8 \%)$ & 95 (4I.1\%) & 60 (52.2\%) & \\
\hline Grade & & & & 0.962 \\
\hline High & 27 (7.8\%) & 18 (7.8\%) & $9(7.8 \%)$ & \\
\hline Moderate & $102(29.5 \%)$ & $66(28.6 \%)$ & $36(31.3 \%)$ & \\
\hline Low & $96(27.7 \%)$ & 65 (28.1\%) & 31 (27.0\%) & \\
\hline Unspecified & $121(35.0 \%)$ & 82 (35.5\%) & 39 (33.9\%) & \\
\hline T stage & & & & 0.055 \\
\hline TI-2 & $120(34.7 \%)$ & 78 (33.8\%) & $42(36.5 \%)$ & \\
\hline T3 & $56(16.2 \%)$ & $4 \mathrm{I}(\mathrm{I7.8 \% )}$ & $15(13.0 \%)$ & \\
\hline $\mathrm{T} 4$ & $96(27.7 \%)$ & $63(27.2 \%)$ & $33(28.7 \%)$ & \\
\hline Tx & 74 (2I.4\%) & 49 (21.2\%) & 25 (21.8\%) & \\
\hline N stage & & & & 0.755 \\
\hline No & $152(43.9 \%)$ & 99 (42.9\%) & $53(46.1 \%)$ & \\
\hline $\mathrm{N}+$ & $136(39.3 \%)$ & 94 (40.7\%) & 42 (36.5\%) & \\
\hline $\mathrm{Nx}$ & $58(16.8 \%)$ & 38 (16.4\%) & 20 (I7.4\%) & \\
\hline Radiation & & & & 0.061 \\
\hline No evidence & 308 (89.0\%) & 200 (86.6\%) & 108 (93.9\%) & \\
\hline Yes & 38 (1 I.0\%) & 31 (I3.4\%) & 7 (6.1\%) & \\
\hline Surgery & & & & 0.986 \\
\hline No surgery & $283(81.8 \%)$ & 189 (81.8\%) & 94 (81.7\%) & \\
\hline Surgery & $63(18.2 \%)$ & 42 (I8.2\%) & $21(18.3 \%)$ & \\
\hline
\end{tabular}

Notes: $P<0.05$ is considered statistically significant. Statistically significant value is shown in bold.

Abbreviation: PSM, propensity score matching. 
Table S2 Baseline characteristics of metastatic ampullary cancer patients after PSM

\begin{tabular}{|c|c|c|c|c|}
\hline \multirow[t]{2}{*}{ Characteristics } & \multirow{2}{*}{$\begin{array}{l}\text { Total } \\
(n=230) \\
\end{array}$} & \multirow{2}{*}{$\begin{array}{l}\text { Chemotherapy } \\
(n=115)\end{array}$} & \multirow{2}{*}{$\begin{array}{l}\text { No chemotherapy } \\
(n=I I 5)\end{array}$} & \multirow[t]{2}{*}{$P$-value } \\
\hline & & & & \\
\hline Age at diagnosis & & & & 0.670 \\
\hline Mean \pm SD & $66.2 \pm 9.2$ & $65.7 \pm 9.0$ & $66.7 \pm 9.3$ & \\
\hline Sex & & & & 0.232 \\
\hline Female & $102(44.4 \%)$ & $46(40.0 \%)$ & $56(48.7 \%)$ & \\
\hline Male & $128(55.6 \%)$ & 69 (60.0\%) & 59 (51.3\%) & \\
\hline Race & & & & 0.380 \\
\hline White & 175 (76.1\%) & $83(72.2 \%)$ & $92(80.0 \%)$ & \\
\hline Black & 31 (13.5\%) & $18(15.6 \%)$ & $13(11.3 \%)$ & \\
\hline Other & $24(10.4 \%)$ & $14(12.2 \%)$ & $10(8.7 \%)$ & \\
\hline Tumor size, cm & & & & 0.409 \\
\hline$<3$ & $58(25.2 \%)$ & $26(22.6 \%)$ & $32(27.8 \%)$ & \\
\hline$\geq 3$ & $62(27.0 \%)$ & $29(25.2 \%)$ & $33(28.7 \%)$ & \\
\hline Unspecified & 110 (47.8\%) & $60(52.2 \%)$ & $50(43.5 \%)$ & \\
\hline Grade & & & & 0.655 \\
\hline High & $16(7.0 \%)$ & $9(7.8 \%)$ & 7 (6.1\%) & \\
\hline Moderate & $67(29.1 \%)$ & $36(31.3 \%)$ & $31(27.0 \%)$ & \\
\hline Low & $60(26.1 \%)$ & $31(27.0 \%)$ & $29(25.2 \%)$ & \\
\hline Unspecified & 87 (37.8\%) & 39 (33.9\%) & 48 (4I.7\%) & \\
\hline T stage & & & & 0.269 \\
\hline TI-2 & $86(37.4 \%)$ & $42(36.5 \%)$ & 44 (38.3\%) & \\
\hline T3 & $28(12.2 \%)$ & $15(13.1 \%)$ & $13(11.3 \%)$ & \\
\hline $\mathrm{T} 4$ & $66(28.7 \%)$ & $33(28.7 \%)$ & $33(28.7 \%)$ & \\
\hline$T x$ & $50(21.7 \%)$ & $25(21.7 \%)$ & $25(21.7 \%)$ & \\
\hline N stage & & & & 0.800 \\
\hline No & I0I (43.9\%) & $53(46.1 \%)$ & 48 (4I.7\%) & \\
\hline $\mathrm{N}+$ & 87 (37.8\%) & $42(36.5 \%)$ & $45(39.1 \%)$ & \\
\hline $\mathrm{Nx}$ & $42(18.2 \%)$ & $20(17.4 \%)$ & $22(19.2 \%)$ & \\
\hline Radiation & & & & 0.079 \\
\hline No evidence & 207 (90.0\%) & 108 (93.9\%) & 99 (86.1\%) & \\
\hline Yes & $23(10.0 \%)$ & 7 (6.1\%) & $16(13.9 \%)$ & \\
\hline Surgery & & & & 0.364 \\
\hline No surgery & 194 (84.3\%) & 94 (81.7\%) & $100(87.0 \%)$ & \\
\hline Surgery & $36(15.7 \%)$ & 21 (18.3\%) & $15(13.0 \%)$ & \\
\hline
\end{tabular}

Notes: PSM was performed according to age and T stage with a caliper of 0.005 . $P<0.05$ is considered statistically significant. Abbreviation: PSM, propensity score matching.

A

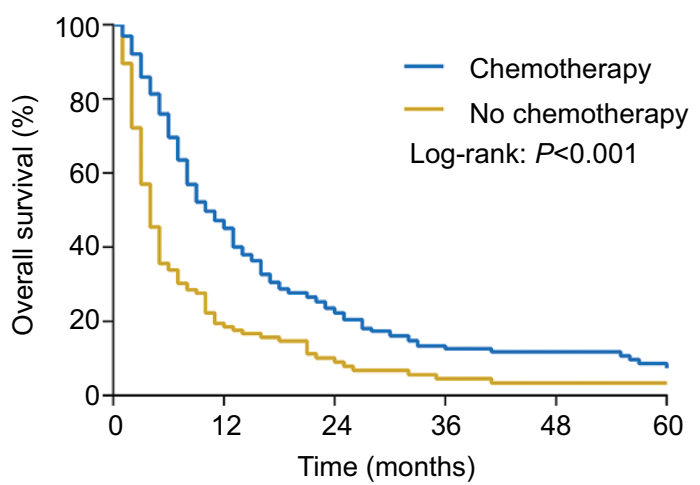

No. at risk

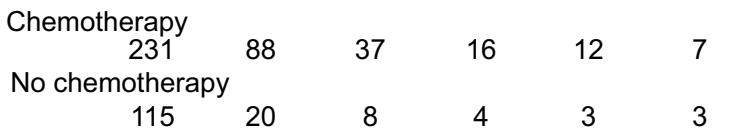

B

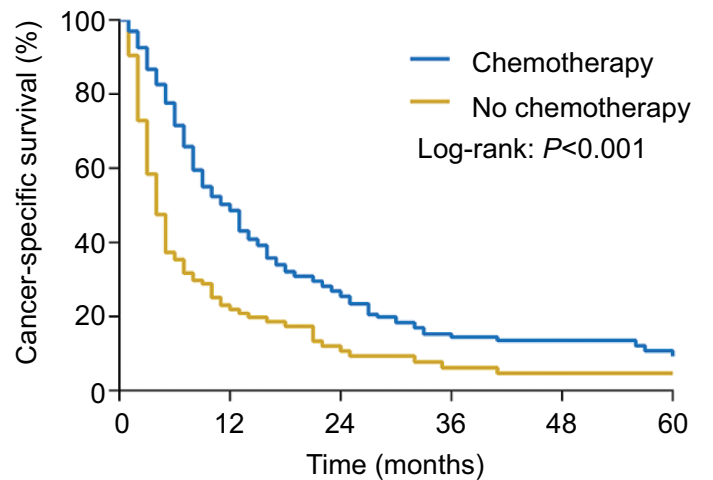

No. at risk

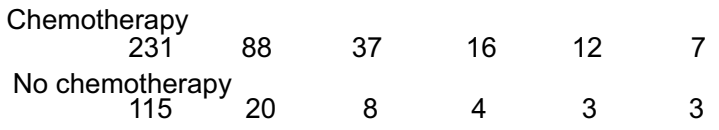

Figure SI Kaplan-Meier curves of overall (A) and cancer-specific survival (B) according to whether chemotherapy was received or not in the overall cohort before PSM $(n=346)$.

Abbreviation: PSM, propensity score matching. 


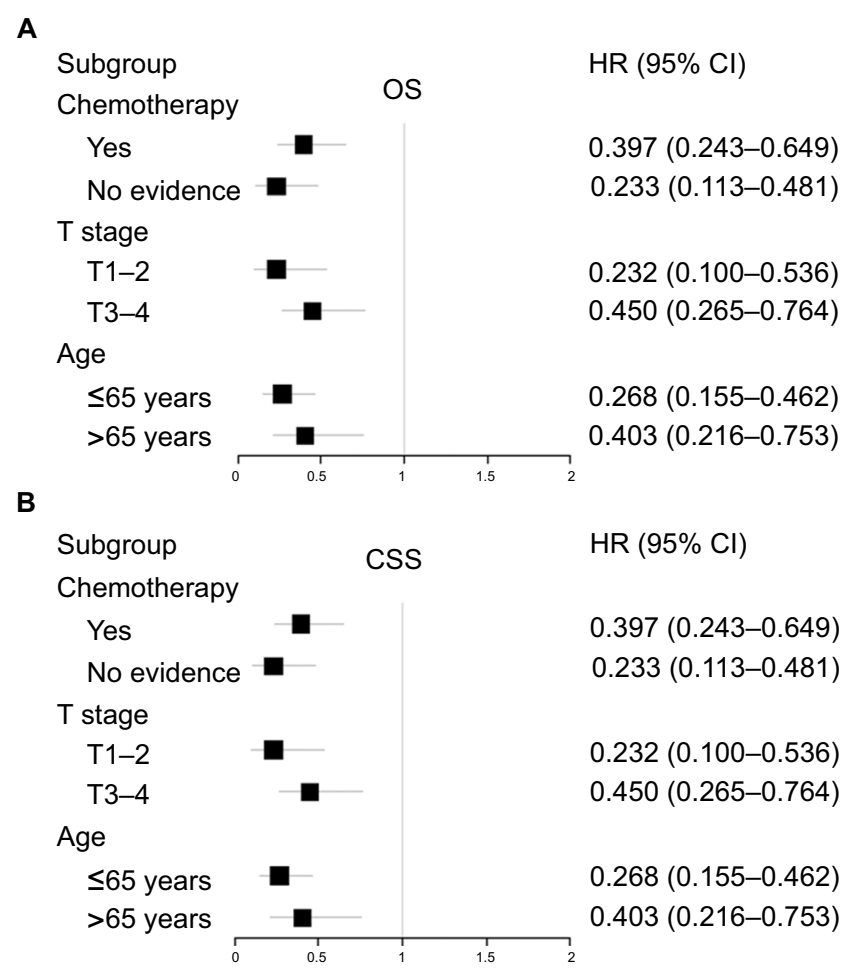

Figure S2 Forest plots summarizing the HRs and $95 \%$ Cls of overall survival (A) and CSS (B) for PTR vs no-PTR in subgroup analyses. Abbreviations: CSS, cancer-specific survival; PSM, propensity score matching; PTR, primary tumor resection.

A

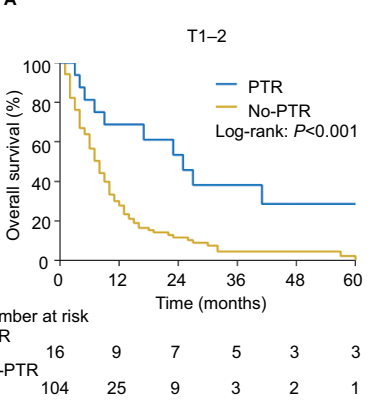

B

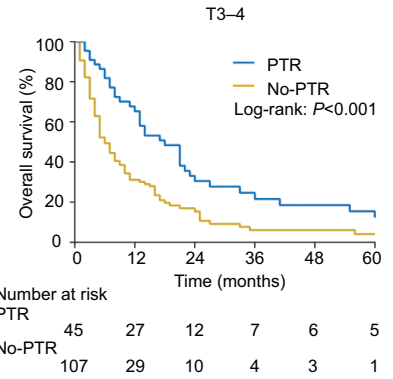

C

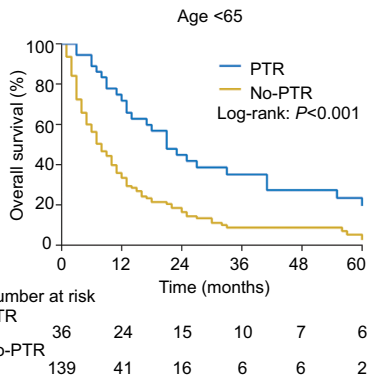

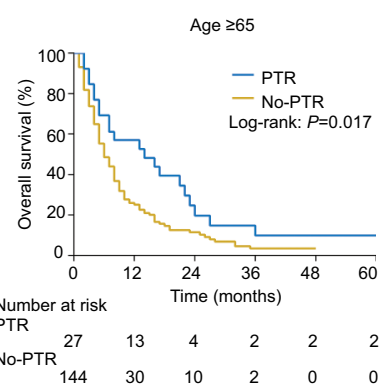

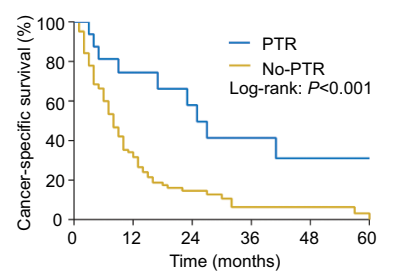
Number at risk
PTR

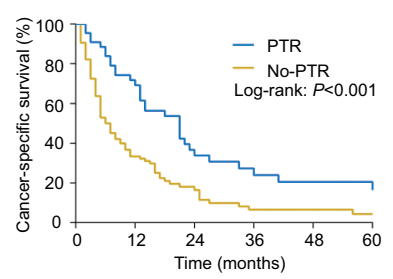
$\begin{array}{lll}\text { Number at risk } & \text { Number at risk } & \text { Time (months) } \\ \text { PTR } & \text { PTR } & \end{array}$

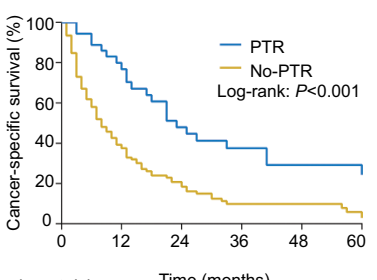
Number at risk
PTR

$$
5 \text { No-P1 }
$$

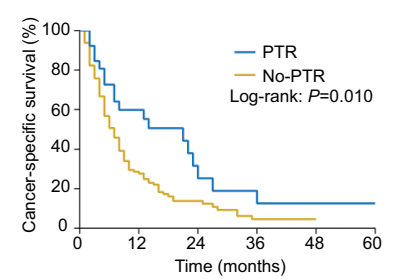

Number at risk PTR

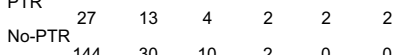

Figure S3 Kaplan-Meier curves of overall and cancer-specific survival according to whether or not PTR was performed in the TI-2 subgroup (A), T3-4 subgroup (B), age $<65$ subgroup (C) and age $\geq 65$ subgroup (D).

Abbreviation: PTR, primary tumor resection. 


\section{Publish your work in this journal}

Cancer Management and Research is an international, peer-reviewed open access journal focusing on cancer research and the optimal use of preventative and integrated treatment interventions to achieve improved outcomes, enhanced survival and quality of life for the cancer patient. The manuscript management system is completely online and includes a very quick and fair peer-review system, which is all easy to use. Visit http://www.dovepress.com/testimonials.php to read real quotes from published authors.

Submit your manuscript here: https://www.dovepress.com/cancer-management-and-research-journal 